\title{
UNSTABLE CRACK PROPAGATION UNDER SEVERE ACCIDENT SCENARIO CONDITIONS IN A PRESSURIZED WATER REACTOR
}

\author{
Nicolas Tardif \\ Institut de Radioprotection et de Sûreté Nucléaire \\ DSR/SAGR/BPhAG \\ BP17, 92262 Fontenay-aux-Roses Cedex \\ Email: nicolas.tardif@insa-lyon.fr
}

\author{
Michel Coret* \\ Alain Combesure \\ Université de Lyon \\ CNRS, INSA / LAMCOS, UMR/CNRS 5259 \\ Bât. J. d'Alembert, 20 avenue Albert Einstein \\ 69621 Villeurbanne Cedex FRANCE \\ Email : \{alain.combescure, michel.coret\}@insa-lyon.fr
}

\begin{abstract}
In the case of a severe accident scenario of a pressurized water reactor which includes cracking of the vessel bottom head, it is crucial to predict the leak rate and hence the crack size for the ex-vessel accident management. We present an experimental framework to analyze the crack propagation under such severe conditions for different 16MND5 French nuclear steel grades. An original experimental setup has been designed in order to perform bi-axial tests (tensile load independent of internal pressure) at high temperatures (1180K - 1280K) on tubular test specimens. The temperature loading and the mechanical loading can be set to reproduce the stress distribution of the hemispherical vessel bottom head submitted to an internal pressure. Moreover, the test was designed to be easily transposable to the real structure in terms of crack propagation and depressurization thanks to an energy based scaling methodology. We observed the crack initiation and propagation with two high speed digital cameras. Force, internal pressure, displacement and temperature fields were also measured and synchronized with the optical measurements. The different creep stages are observed and characterized. The crack propagation and opening history have been measured. During crack initiation and propagation stages, the depressurization can be correlated with the crack geometry. Finally, the setup has been designed in order to validate future numerical analysis.
\end{abstract}

\footnotetext{
*Address all correspondence to this author.
}

\section{NOMENCLATURE}

PWR Pressure Water Reactor.

LHF Lower Head Failure.

OLHF OECD Lower Head Failure.

RCS Reactor Coolant System.

$\alpha$ Vessel bottom head's angular position.

$\rho$ Density.

$\sigma_{z z}$ Nominal tensile stress.

$\sigma_{\theta \theta}$ Nominal circumferential stress.

$R$ Radius.

$e$ Thickness.

$p$ Relative pressure.

$F$ Machine tensile force.

$V$ Pressurized gas volume.

$G_{c}$ Energy release rate.

a Crack's length.

$v_{l l} \quad$ Load line displacement.

$\mathcal{A}$ Crack's area.

$E_{p l}$ Irreversible strain energy.

$\Gamma_{0} \quad$ Surface energy release rate.

$R$ Toughness (Turner definition).

\section{INTRODUCTION}

The paper context is the simulation of the rupture of a pressurized water reactor (PWR) vessel bottom head under severe accident conditions (figure 1). Multiple malfunctions cause the 
fuel degradation by the reactor core melting. The reactor core melting causes the formation of a highly calorific corium melt (mixing of the melt core and the melt material of the structure) down on the vessel bottom head. Consequently, the vessel bottom head is submitted to a significant thermal and mechanical loading. Indeed, the corium melt heats locally the vessel bottom head's wall at high temperature $(\geq 1180 \mathrm{~K})$ by direct contact and induces the alteration of its material behaviour. At the same time, the pressure in the vessel is supposed to reach $2.5 \mathrm{MPa}$. Under these severe conditions, cracking could occur by creep.

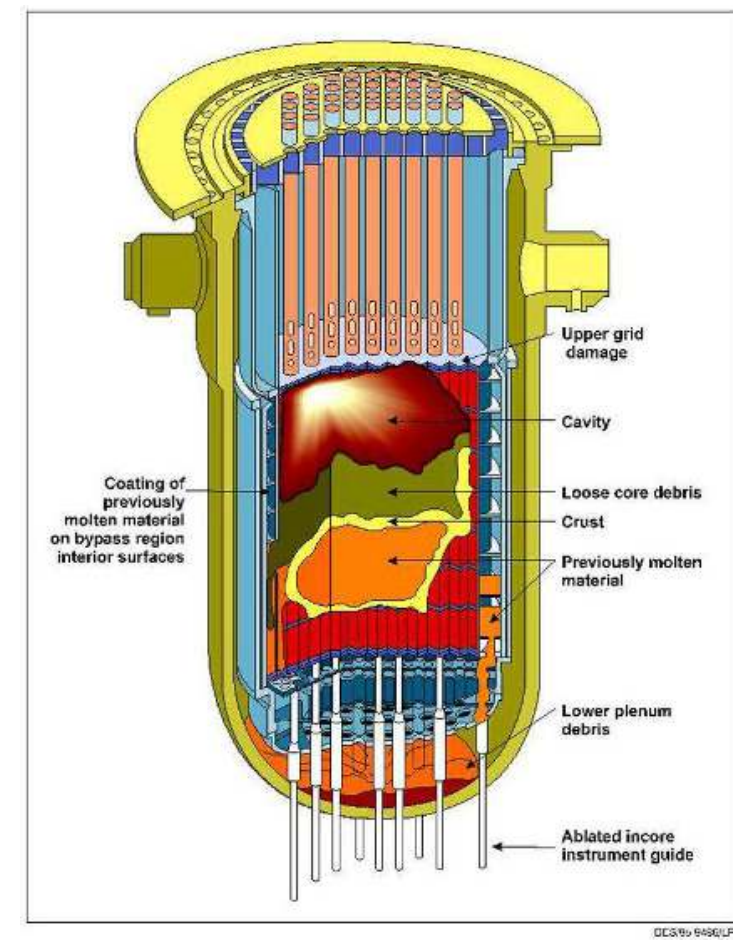

Figure 1. SEVERE ACCIDENT

In the case of this highly hypothetical scenario, it is crucial to predict the localization, the size of the crack and the time before its initiation because these parameters have a strong influence on the management of the ex-vessel accident.

Tests were already carried out, to adress this type of problem in American reactors, with an about fifth scale bottom head model through the programs Lower Head Failure and OECD Lower Head Failure (LHF and OLHF [1] [2]). During these tests, the mock-ups were in broad submitted to a scaled constant internal pressure and a scaled slope in temperature until rupture by creep. The influence of the temperature distribution (uniform, center peaked, side peaked), the influence of the pressure magnitude (low to high reactor coolant system pressure, 2 to $10 \mathrm{MPa}$ ), the influence of a transcient in pressure and the influence of a through-wall temperature differential $(200$ - 400K) were mainly regarded. In addition with the results on deformations and time at crack's initiation, these tests showed the behaviour variability of the material of the American bottom head at $1280 \mathrm{~K}$ which led to more or less ductile fracture [3,4]. The FOREVER tests [5] [6], carried out with a tenth scale vessel model, mainly differed from the LHF-OLHF tests by the heating device. The Corium melt was simulated by heating of a binary salt. Therefore, the effect of the convection on the temperature distribution along the height of the mock-up's wall were studied. The tests led to the same conclusions about the material behaviour variability as the LHFOLHF tests for the French material. Some simplified numerical analysis were made in order to simulate these tests [7-10]. From this established fact, a lot of tests were carried out in order to characterize the French material behaviour (16MND5) according to its steel grades [11].

An original experimental setup has been designed in order to perform bi-axial tests (tensile load independent of internal pressure) at high temperatures $(1180 \mathrm{~K}-1280 \mathrm{~K})$ on tubular test specimens. The temperature loading and the mechanical loading can be set to reproduce the stress distribution of the hemispherical vessel bottom head submitted to an internal pressure. Moreover, the test was designed to be easily transposable to the real structure in terms of crack propagation and depressurization thanks to an energy based scaling methodology. We observed the crack initiation and propagation with two high speed digital cameras. Force, internal pressure, displacement and temperature fields were also measured and synchronized with the optical measurements.

This paper presents firstly the PWR accident conditions modelling. The choice of the specimen geometry, the choice of the material and the choice of the thermal and mechanical loadings are argued in order to reach a good cracking and depressurization transposition. Then, the test device is described. Eventually, a section deals with an example of reached results in terms of loadings validation, crack propagation and depressurization.

\section{PWR ACCIDENT CONDITION MODELLING}

The scaling values are carried forward in the table 1 .

\section{Geometry of the test specimen}

For practical reasons, the crack tips position can more easily be determined for a test specimen with a tubular geometry, rather than a hemispherical geometry (which is more representative of the vessel bottom head). Consequently, the effective area of the specimen (figure 2) are made of a $24 \mathrm{~mm}$ external diameter and $10 \mathrm{~mm}$ long tube. Its wall is $0.8 \mathrm{~mm}$ thick. Therefore, the ratio between the internal radius and the wall thickness is similar to the reactor case. 
The geometry was obtained by turning and resurfacing. The wall thickness of the effective area was then measured in 12 points thanks to a 3D measuring machine. The maximal thickness range measured on a specimen was $0.037 \mathrm{~mm}$.

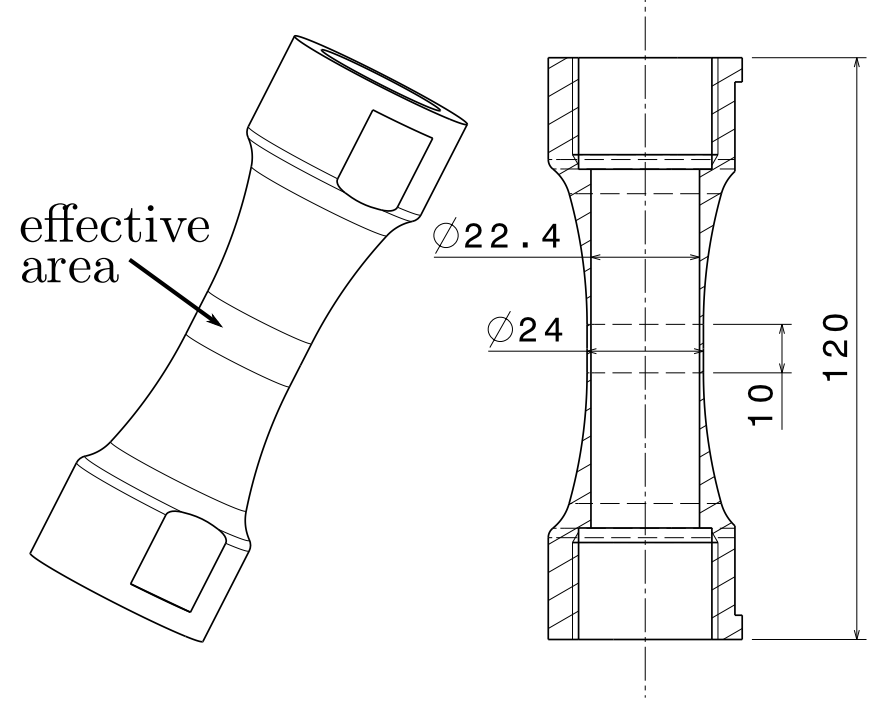

Figure 2. TEST SPECIMEN GEOMETRY

\section{Material}

Two different French 16MND5 steel grades were studied. One steel grade called "Rupther" is ductile at high temperature and the second one called "Krakatoa" is more brittle at high temperature.

The effect of the material irradiation was not studied here. The material has been kept aside at the PWR vessels production.

\section{Loading}

The loading has to be as similar as possible to the reactor case, it must account for :

- the vessel bottom head heating by direct contact with the corium.

- the mechanical loading induced by the internal pressure and by the corium weight in the wall of the vessel bottom head.

Thermal loading The Forever tests showed the temperature distribution in the vessel submitted to a binary salt melt that simulated the corium melt. The convection effects on the temperature distribution have thus been studied. The temperature distribution was uniform on a latitude, and the warmest latitudes were the nearest of the melt surface. Therefore, we have chosen to heat uniformly the effective area of the specimen at $1180 \mathrm{~K}$ and $1280 \mathrm{~K}$, considering that the warmest latitude was accounted for. However, given this loading and the specimen wall thickness, we did not take into account the effect of the temperature gradient in the vessel bottom head wall (radial direction). It had already been done in the OLHF tests [1].

Mechanical loading The stress state of the Vessel bottom head at the beginning of the accident is illustrated in figure 3. Considering the $1300 \mathrm{MW}$ French PWR geometry, the membrane stress maximum value and the membrane stress ratio are drawn near the internal radius. The Vessel is submitted to a $2.5 \mathrm{MPa}$ internal pressure and a 241 ton corium weight $\left(\rho=7000 \mathrm{~kg} \cdot \mathrm{m}^{-3}\right)$, that corresponds to the maximal corium volume. The figure shows that the corium weight has a little influence on the stress state of the Vessel bottom head. We can also notice that the membrane stress ratio is comprised between 1 and 1.6 .

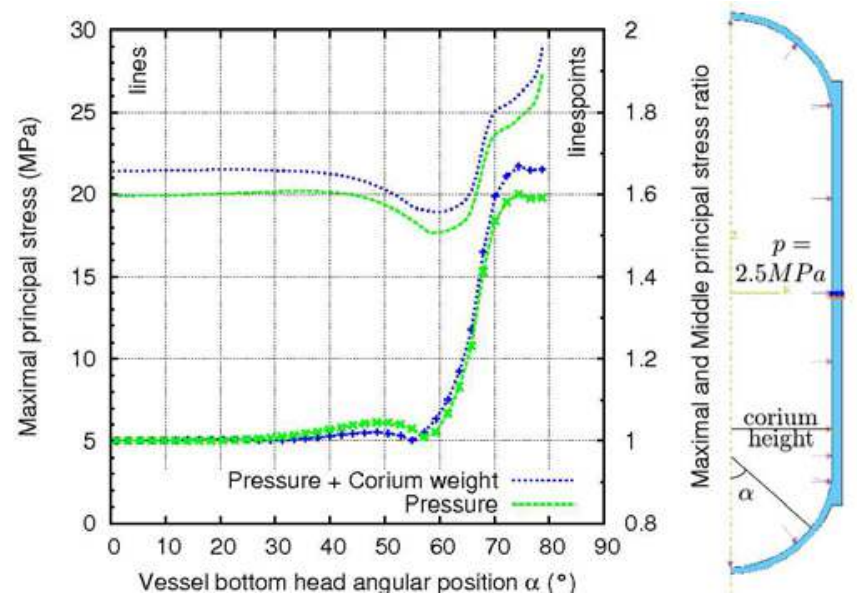

Figure 3. MEMBRANE STRESS DISTRIBUTION

Under the thin wall assumption, a tubular piece with a radius $R$ and a thickness $e$ submitted to a pressure $p$ is in the following stress state :

$$
\sigma=\left[\begin{array}{ccc}
p & 0 & 0 \\
0 & \frac{p R}{e} & 0 \\
0 & 0 & 0
\end{array}\right]_{\left(\mathbf{e}_{\mathbf{r}}, \mathbf{e}_{\theta}, \mathbf{e}_{\mathbf{z}}\right)}
$$

Consequently, we had to add a tensile loading, so that $\sigma_{z z}=$ $k . \sigma_{\theta \theta}$, in order to reproduce the mechanical loading of the vessel bottom head. For practical reasons, we want a crack propagation 
in a plane which is normal to the axis of the tube. So we imposed a tensile loading so that $k \geq 1$.

We chose a $2.5 \mathrm{MPa}$ internal pressure value and a $1.65 \mathrm{k}$ value at the internal radius.

Loading management Several loading sequencings can be carried out.

During the OLHF tests, the thermal loading (susceptor radiation) was first applied until a temperature that induced no creep deformation. Then, the pressure plateau was applied. Eventually, a slope of temperature was applied until rupture.

During the FOREVER tests, the thermal loading (resistive heating of a binary salt melt) was applied until the specimen wall reachs a thermal balance. Then the pressure loading was applied until rupture.

Our loading management was similar to the FOREVER tests sequencing. We applied a $2.5 K . s^{-1}$ slope of temperature until the aimed one $(1180 \mathrm{~K}$ or $1280 \mathrm{~K})$ and we maintained this temperature until rupture. At the beginning of the thermal plateau, we imposed a $0.125 \mathrm{MPa} . \mathrm{s}^{-1}$ and $120 \mathrm{~N} . \mathrm{s}^{-1}$ slope until $2.5 \mathrm{MPa}$ and $2400 N$. Then we maintained the mechanical loading until rupture.

We have chosen to keep the temperature constant to make the numerical analysis easier because we will not have to simulate the material beahaviour variabilty due to the temperature. With this loading sequencing, we also did not take into account the problems of transformation plasticity [12] which could take place during the phase transition of the material under a stress loading.

Scaling method of the mechanical loading We had to scale the volume of pressurized gas which was available for the mechanical loading. Indeed, the volume of gas affects the depressurization speed and the crack propagation depends on the pressure loading.

The scaling method applied concerns the ratio between the energy that was nessessary for the complete circumference cracking of the structure and the energy which was available in the pressurized gas volume. It has to be the same at both scale one and model scale. For the same material, it corresponds to this equation :

$$
\frac{p_{r} \cdot V_{r}}{G_{c} \cdot e_{r} \cdot a_{r}}=\frac{p_{s} \cdot V_{s}}{G_{c} \cdot e_{s} \cdot a_{s}}
$$

where $p$ the internal pressure, $V$ the volume of gas available for the loading, $G_{c}$ the energy release rate in a pure mode $1, e$ the wall thickness, $a$ the crack length. the index ${ }_{r}$ for the reactor and ${ }_{s}$ for the specimen.

\begin{tabular}{|c|c|c|c|}
\hline & $\begin{array}{c}\text { 1300MW } \\
\text { French Reactor }\end{array}$ & Specimen & $\begin{array}{l}\text { Ratio } \\
\frac{\text { Reactor }}{\text { Specimen }}\end{array}$ \\
\hline & \multicolumn{3}{|c|}{ Geometry } \\
\hline Internal radius $R_{i}$ & $2.2 \mathrm{~m}$ & $11.2 \mathrm{~mm}$ & 196.4 \\
\hline Wall thickness $e$ & $0.14 \mathrm{~m}$ & $0.8 \mathrm{~mm}$ & 175 \\
\hline \multirow[t]{2}{*}{ Ratio $\frac{R_{i}}{e}$} & 15.714 & 14 & 1.12 \\
\hline & \multicolumn{3}{|c|}{ Loading at the internal radius } \\
\hline Pressure & $2.5 \mathrm{MPa}$ & $2.5 \mathrm{MPa}$ & 1 \\
\hline $\begin{array}{c}\text { Maximum } \\
\text { membrane stress }\end{array}$ & $20-25 \mathrm{MPa}$ & $58 \mathrm{MPa}$ & \\
\hline $\begin{array}{c}\text { Membrane stress } \\
\text { ratio }: \frac{\sigma_{z z}}{\sigma_{\theta \theta}}\end{array}$ & $1-1.6$ & 1.65 & \\
\hline Gaz volume & $370 m^{3}$ & $21 \mathrm{dm}^{3}$ & \\
\hline $\begin{array}{l}\text { Volume scaling } \\
\frac{\text { Pressurized gas energy }}{\text { Rupture energy }}\end{array}$ & $1 \mathrm{~m}^{*}$ & & 1.13 \\
\hline
\end{tabular}

* Value of the cracking latitude radius

Table 1. SCALING OF THE MOCK-UP

\section{Assumption about the crack propagation behaviour}

The specimen geometry and the pressure loading induced a higher initial stress state than in the 1300MW reactor case. So the initial condition in the experiment corresponded to a vessel bottom head state which had already crept. Consequently, we suppose that the crack propagation behaviour does not depend on the initial condition but only on the stress state at the crack initiation.

The priority was given to a cracking behaviour and depressurization simulation rather than a time to initiation transposition.

\section{EXPERIMENTAL DEVICE}

The specimen was placed in an enclosure for securiy reasons. The enclosure had 3 portholes to enable the optical measurements. The experimental device is presented in figure 4.

\section{Mechanical loading}

The circumferential stress $\sigma_{\theta \theta}$ was provided by an internal pressure. The pressurized gas was argon. It was controlled by a pressure regulator and measured as close as possible from the crack with two gauge sensors. A $20 \mathrm{dm}^{3}$ cylinder was put downstream the pressure regulator in order to control the pressurized gas volume. 


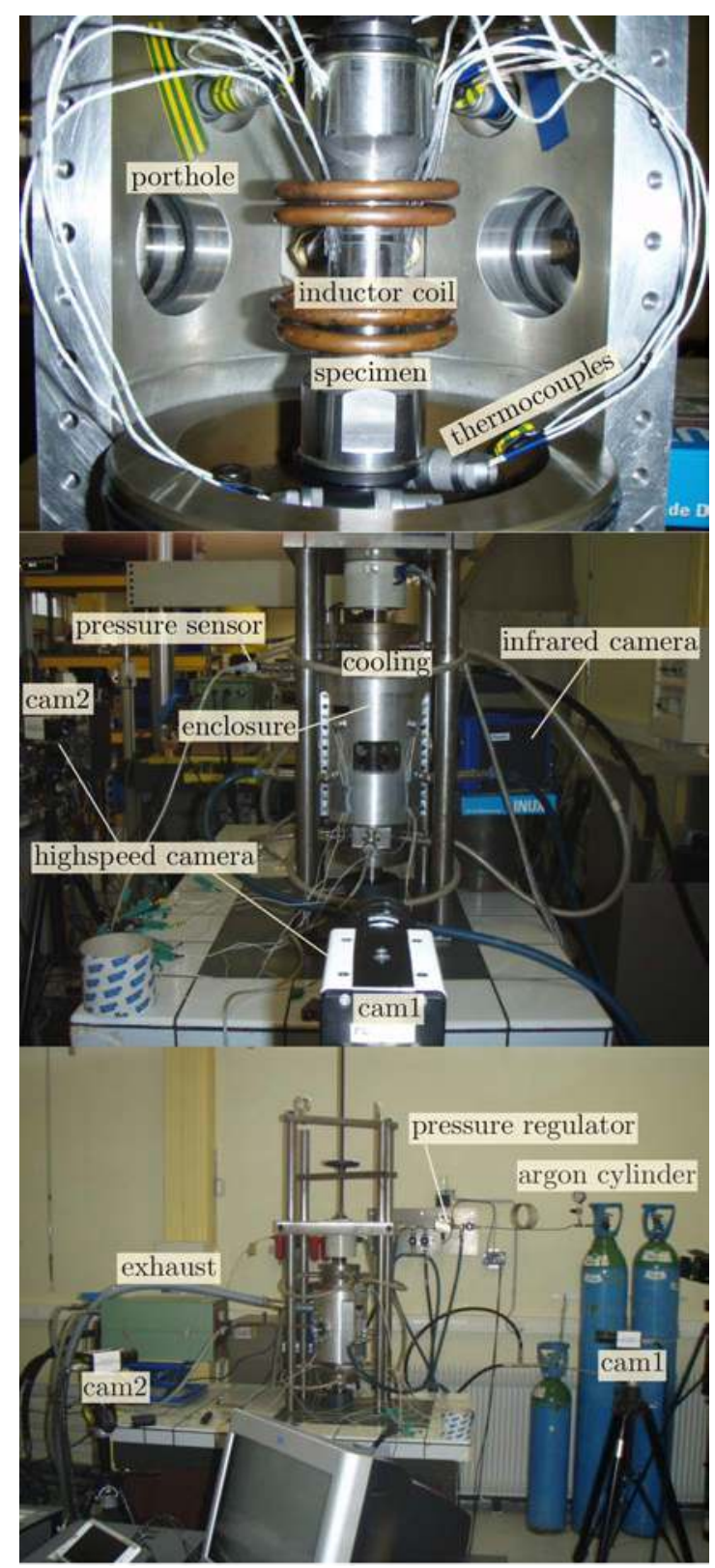

Figure 4. EXPERIMENTAL DEVICE

The axial stress $\sigma_{z z}$ was partly applied by the pressure bottom effect, and partly, by a $20 \mathrm{kN}$ hydraulic tensile machine. This part of the force was measured using the machine load cell. The displacement of the cylinder was also measured by the machine displacement sensor.

\section{Thermal loading}

The thermal loading was applied by an inductor heating. The power generator capacity was $6 \mathrm{~kW}$. It was controlled by a type
K thermocouple.

The tensile machine grips were cooled with water.

The temperature information was obtained locally by eight thermocouples (+ the reference one). All the thermocouples were spot-welded on the external surface of the specimen. Three thermocouples were distributed on the circumference of the specimen effective area. The others were distributed on the specimen half-height (numerical analysis requirement).

We also measured the temperature distribution in a halfcircumference of the effective area using a CEDIP infrared camera which recorded at 177f/s $\left(320 \times 256 p x^{2}\right)$. The porthole used for the infrared camera was made of Sapphire to let the infrared spectrum pass. The specimen effective area was painted with a graphite airbrush in order to control the emissivity.

\section{Crack path determination}

We obtained the crack's tips position thanks to two highspeed digital cameras and thanks to the infrared camera. The highspeed digital cameras enabled us to record the duration of the test at $25 \mathrm{f} / \mathrm{s}$ and the last $4 \mathrm{~s}$ at $1000 \mathrm{f} / \mathrm{s}\left(400 \mathrm{x} 400 p x^{2}\right)$. So, the entire circumference was seen during the totality of the test.

Before the mechanical and thermal loading, the enclosure atmosphere was replaced with argon to avoid the appearance of oxydation plates that could disturb the optical measure.

All the measurement devices (apart the infrared camera) were synchronized on the same time base.

\section{RESULTS}

This section illustrates the results that we obtained with the experimental device. We present a test performed at $1180 \mathrm{~K}$ on the "Rupther" 16MND5 steel grade. The average specimen thickness measured was $0.797 \mathrm{~mm}$, all the points were comprised between $0.783 \mathrm{~mm}$ and $0.807 \mathrm{~mm}$. The cameras were positioned as shown in figure 4 .

\section{Thermal loading}

At the beginning of the mechanical loading, the temperature was homogeneous at $\pm 20 \mathrm{~K}$ in the effective area (Thermocouples and infrared camera measurement). The temperature distribution is presented in figure 5 and can be considered as symetric on the other side of the specimen. The specimen was warmer at the side of the inductor coil transition curve.

\section{Mechanical loading}

The mechanical loading is presented in figures 6(a) and 6(b). The membrane stresses are calculated from the initial geometry of the specimen (internal radius $R_{i}$, external radius $R_{e}$, wall thickness $e$ ) with the measurement of the Force $F$ and the relative pressure $p$ : 


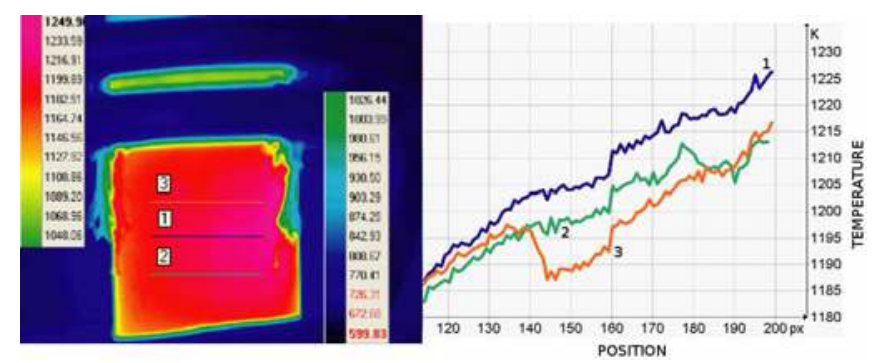

Figure 5. TEMPERATURE DISTRIBUTION

$$
\begin{aligned}
\sigma_{z z} & =\frac{F}{\pi\left(R_{e}^{2}-R_{i}^{2}\right)}+p \frac{R_{i}^{2}}{R_{e}^{2}-R_{i}^{2}}, \\
\sigma_{\theta \theta} & =p \frac{R_{i}}{e} .
\end{aligned}
$$

In figure 6(a), we can see on the displacement curve the primary, secondary and tertiary creep of the specimen at high temperature under the bi-axial loading. The displacement value at the beginning of the mechanical loading is due to the thermal strain. The transition between the secondary and the tertiary creep is approximately situated at 650s (about 200s after the mechanical loading application) for a $5.25 \mathrm{~mm}$ load line displacement.

\section{Crack propagation}

The crack initiation occured on the side of the infrared camera ( figure 7). The crack initiation corresponded to a local cooling of the specimen wall due to the gas expansion. It occured at about $682.027 \mathrm{~s}$ (about 230s after the mechanical loading, $1746 \mathrm{~ms}$ before the complete rupture).

From the pictures of the three cameras, we can recover the crack propagation. The circumferential crack propagation is shown in figure 8.

At the beginning of the propagation (from 1750 to $1250 \mathrm{~ms}$ prior to the complete rupture), the propagation was stable. The crack propagation speeds were less than $0.030 \mathrm{~m}_{\mathrm{s}} \mathrm{s}^{-1}$.

Then there was a crack arrest. It can be explained by two phenomena : the crack lips cooling that stiffened the material and the decrease of the loading due to the depressurization. The force applied by the tensile machine remained constant whereas the depressurization occured. Therefore, the structure keeps on creeping. In the real case, the crack would probably remain in this state. However, it is difficult to forecast the role of the corium melt evacuation on the crack lip cooling.

From $-100 \mathrm{~ms}$, the crack propagation becomed unstable. The crack speed reached about $3 m . s^{-1}$.

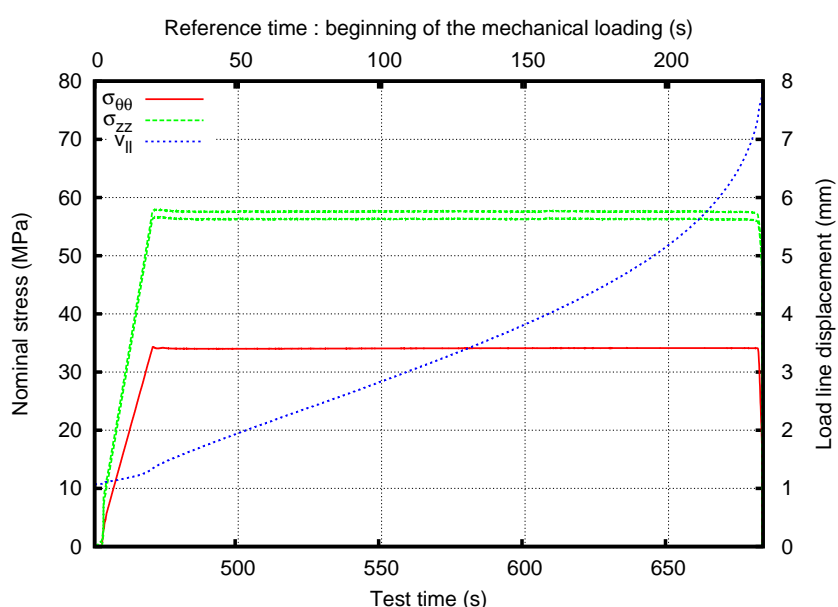

(a) ENTIRE

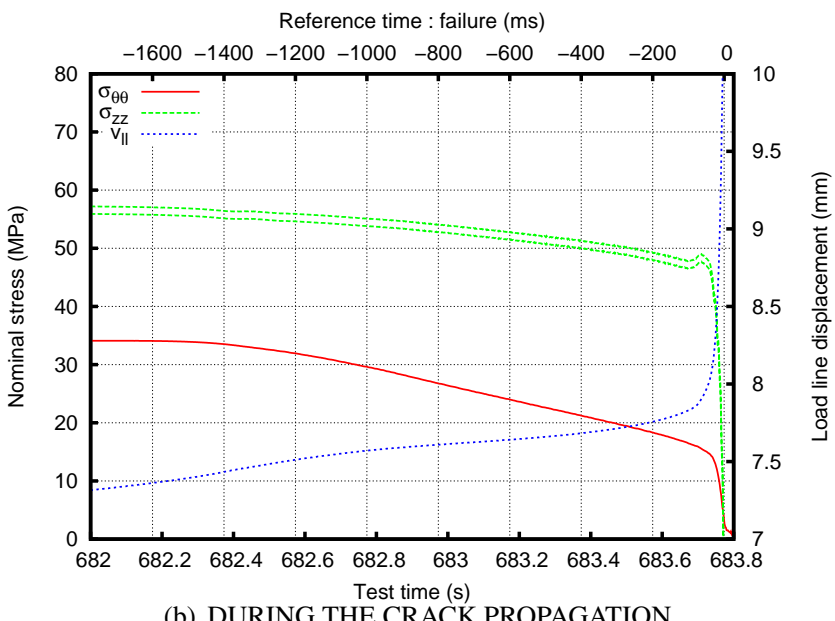

(b) DURING THE CRACK PROPAGATION

Figure 6. MECHANICAL LOADING

We can explain the different steps of the propagation thanks to the work of Turner and Kolednik [13]. The total crack growth resistance $R$ of a material can be defined as total non reversible energy which is necessary to extend the crack area by an increment of $d \mathcal{A}$. The energy is consumed by two phenomen, $d E_{p l}$ denotes the extent of the total non reversible strain energy consumed during the fracture process and $\Gamma_{0}$ the surface energy release rate required for the crack lips nucleation :

$$
R=\frac{d E_{p l}}{d \mathcal{A}}+\Gamma_{0}
$$

This approach has been developed in the case of the ductile material. We extend this approach to a viscoplastic material to explain the crack propagation. However, we recognize that, in our case, the crack growth resistance depends on the scale effect, 


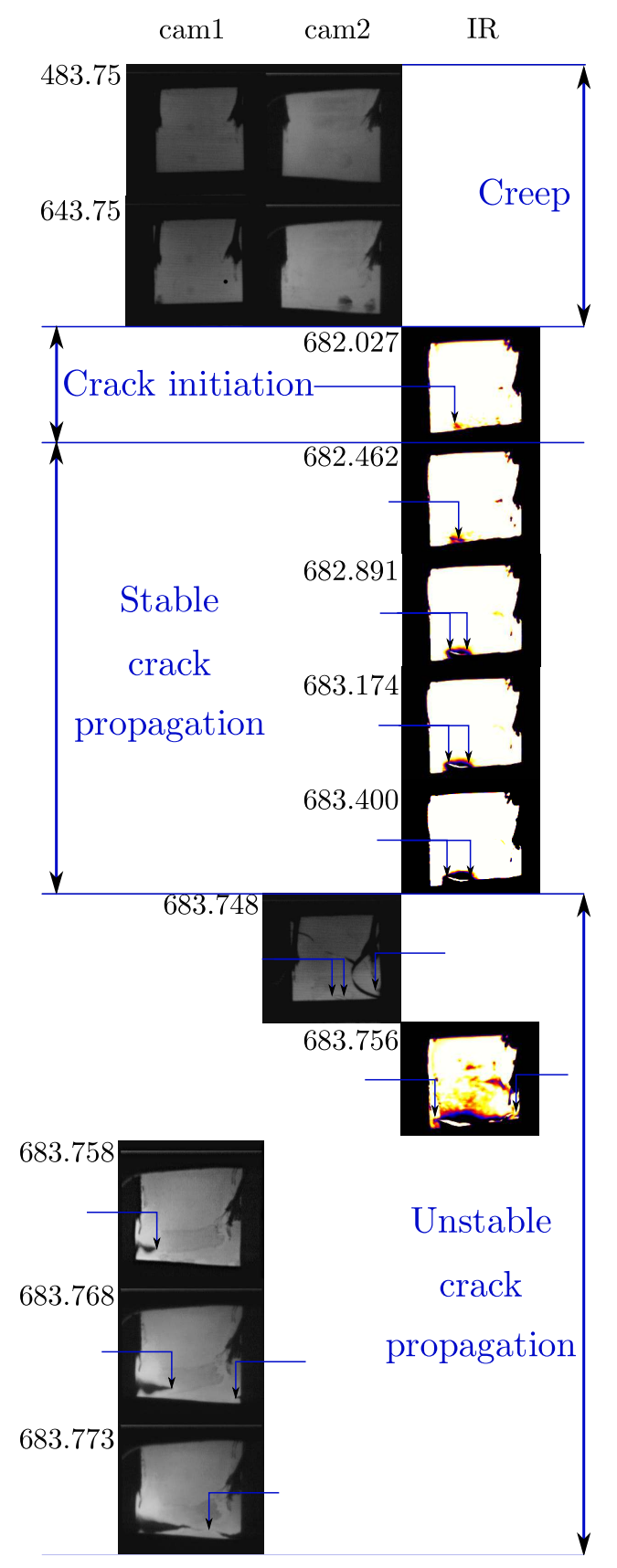

Figure 7. TEST PICTURES

because the irreversible strain energy is not simply due to the crack singularity.

During the first two steps, $R$ is very important because $\frac{d E_{p l}}{d \mathscr{A}}$ is very important. It is even more true in the second step. In contrast, during the last stage, $R$ is much smaller, because $\frac{d E_{p l}}{d \mathscr{A}}$ is very small. Indeed, the necking of the entire wall at the crack path has already occured.

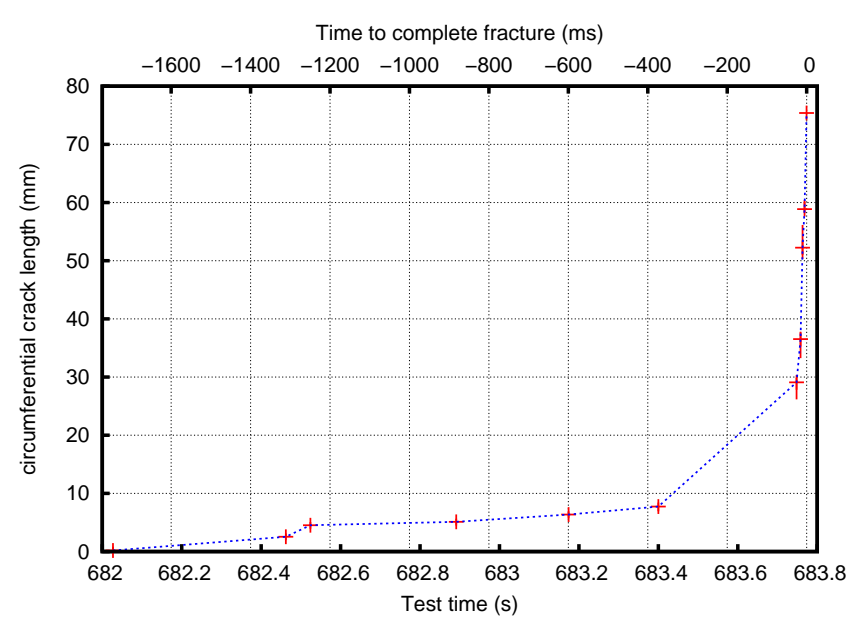

Figure 8. CRACK PROPAGATION

\section{Depressurization}

The experimental device also enables us to obtain an experimental depressurization that can be correlated to the time and the increase of the cracked area. It may be used to fit some depressurization analytical laws. The Depressurization is shown in figure 9.

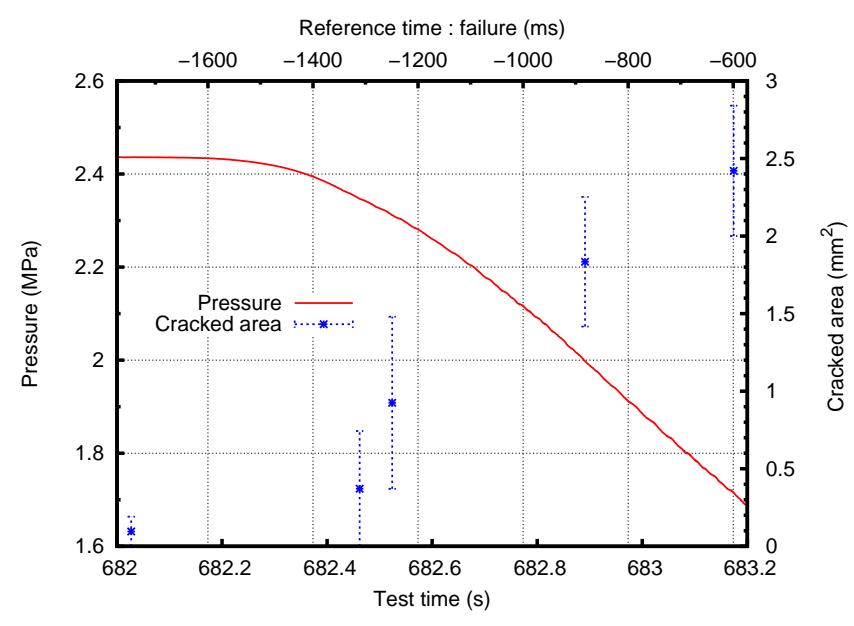

Figure 9. DEPRESSURIZATION

\section{CONCLUSION}

To characterize the corium leak rate in the case of a cracking of a vessel during a severe accident scenario in a pressurized water reactor, an experimental device has been designed. It enables reproduction of the thermal and mechanical conditions of the vessel bottom head during the accident. 
The modelling has been carried out in order to reach a good transposition in terms of gas depressurization and crack propagation. A tubular geometry was used to make the optical measurement of the cracking easier. The effective area was geometrically scaled with the vessel bottom head of a 1300MW French reactor. The tests were carried out from $1180 \mathrm{~K}$ to $1280 \mathrm{~K}$ and $2.5 \mathrm{MPa}$ (temperature and pressure scaled). The mechanical loading was set to reproduce a membrane stress ratio which is similar to the real case. Eventually, the pressurized gas volume was scaled thanks to an energetic transposition.

The experimental device enabled us to perfectly control the thermal and mechanical loading. The crack initition and propagation was measured on the entire circumference of the specimen thanks to two highspeed digital cameras and one infrared camera. This measurement enabled us to correlate the gas depressurization with the cracked area and with the time. This correlation is very conveniant to fit analytical depressurization laws.

Therefore, thanks to the technology used, a detailed analysis of the tests will be relevant to explain the variability of the fracture behavior encountered in previous tests.

Eventually, the combination of the choice of a simple tubular geometry and the implementation of a broad spectrum of measures, will facilitate the numerical analysis of the tests.

\section{ACKNOWLEDGMENT}

This work is funded by IRSN (Institut de Radioprotection et de sûreté nucléaire) and CEA (Commissariat l'énergie atomique) through the project "Cinétique brèche".

\section{REFERENCES}

[1] Chu, T. Y., and al, 1998. Lower Head Failure Experiments and Analyses. Tech. Rep. Report NUREG/CR-5582, SAND98-2047.

[2] Humphries, L. L., and al, 2002. OECD Lower Head Failure project Final report. Tech. Rep. Report OECD/NEA/CSNI/2(2002)27, OECD.

[3] OLIS, ed., 2002. OLHF Seminar 2002, OECD.

[4] Nicolas, L., 1996. RUPTHER - Traction a hautes temperature. Tech. Rep. Report No. DMT 96-381 (in French), CEA.

[5] Sehgal, B., and al, 2005. "Assessment of reactor vessel integrity (ARVI)". Nuclear Engineering and Design, 235, pp. 213-232.

[6] Sehgal, B., and al, 2003. “Assessment of reactor vessel integrity (ARVI)". Nuclear Engineering and Design, 221, pp. 23-53.

[7] Koundy, V., Durin, M., Nicolas, L., and Combescure, A., 2005. "Simplified modeling of a PWR reactor pressure vessel lower head failure in the case of a severe accident". Nuclear Engineering and Design, 235, pp. 835-843.
[8] Koundy, V., and Cormeau, I., 2005. "Semi-analytical modeling of a PWR lower head failure under severe accident conditions using an axisymetrical shell theory". Nuclear Engineering and Design, 235, pp. 845-853.

[9] Koundy, V., and Hoang, N. H., 2008. "Modelling of PWR lower head failure under severe accident loading using improved shells of revolution theory". Nuclear Engineering and Design, 238, pp. 2400-2410.

[10] Koundy, V., Fichot, F., Willschuetz, H. G., Altstadt, E., Nicolas, L., Lamy, J. S., and Flandi, L., 2008. "Progress on PWR lower head failure predictive models". Nuclear Engineering and Design, 238, pp. 2420-2429.

[11] Koundy, V., Caroli, C., Nicolas, L., Matheron, P., Gentzbittel, J. M., and Coret, M., 2008. "Study of tearing behaviour of a PWR reactor pressure vessel lower head under severe accident loadings". Nuclear Engineering and Design, 238, pp. 2411-2419.

[12] Coret, M., Calloch, S., and Combescure, A., 2002. "Experimental study of the phase transformation plasticity of 16MND5 low carbon steel under multiaxial loading". International Journal of Plasticity, 18, pp. 1707-1727.

[13] Turner, C. E., and Kolednik, O., 1994. "A micro and macro approach to the energy dissipation rate model of stable ductile crack growth". Fatigue Fract Engng Mat Struct, 17, p. 10891107. 